came from India. From Germany came 73, Scandinavian countries 47, Switzerland 30, France 25, Holland 21; from Australia 30, New Zealand 27, Canada and Newfoundland 45, the United States 43, South Africa 37, Egypt 26, Palestine 28, China 35. For some years past the College reports have directed attention to the increase in the number of postgraduate and research students. Last year these advanced students numbered 616 , and it is noteworthy that more than 40 per cent of them were from abroad, including 81 from India, 24 from Canada and Newfoundland, 23 from China, 22 from New Zealand, 18 from Australia, 18 from South Africa, 10 from the United States and 10 from Germany. A list of more than five hundred original papers and other publications from the various departments of the College in 1937 is appended to the report. A coloured plan shows graphically the growth of the College site and buildings since 1827 .

\section{Health of School Children}

THe annual report for 1936 of the chief medical officer of the Board of Education, Sir Arthur MacNalty, entitled "The Health of the School Child" (London: H.M. Stationery Office. 2s. 2d., postage included) states that, during the year in question, the nutrition of more than $1,700,000$ children was assessed with the result that $\mathbf{1 4 \cdot 6}$ per cent were regarded as excellent, 74.2 as normal, $10 \cdot 5$ as slightly subnormal and 0.7 as bad; these figures are substantially the same as those in the report for the previous year. Free school meals provided have increased from $87,000,000$ in $1935-36$ to more than $100,000,000$ in 1936-37. More than half the children who could receive milk either free or at half-price still fail to take it. Medical inspection and eyesight, care of the teeth, physical training and recreation and the national health campaign are some of the other subjects dealt with in this report.

\section{Netherlands Indies}

THE Colonial Institute of Amsterdam, which maintains a research department and an economic museum as well as an ethnographical department in conjunction with the Netherlands Pacific Institute, has published the first number of a new quarterly entitled Bulletin of the Colonial Institute of Amsterdam (18s. a year). The aim of the new publication is to give authoritative articles in English on various aspects of the Netherlands Indies. Only a small part of each number will be written in Dutch. Articles of scientific interest in the first number treat of malaria in the Netherlands Indies, social organizations of the peoples of Borneo, Celebes and the Moluceas, and air transport in the Pacific.

\section{Asbestos}

A RECENT publication of the Mineral Resources Department, Imperial Institute, is a monograph on asbestos by Mr. G. E. Howling (second edition. 2s.). The volume includes a discussion of occurrence, mining methods, uses, marketing and world production, and ends with a full bibliography.

\section{Universal Esperanto Congress}

ThE thirtieth Universal Esperanto Congress will be held in London on July 30-August 6, under the high patronage of H.R.H. the Duke of Connaught. The total membership of the Congress is expected to be about 1,500 , of whom some 1,300, representing twentyfive nationalities, had been enrolled at the beginning of June. The official proceedings will, as usual on these occasions, be carried on in the international language alone, no interpreters being employed either at the general meetings or at the sectional gatherings of specialists. Among the social features of the week will be two performances in Esperanto of "Eliza Comes to Stay" by members of the NeilsonTerry Guild of Dramatic Art, who have been learning the language for the purpose. It has been decided to hold next year's Congress at Bern, Switzerland.

\section{The Night Sky in July}

THE moon is full on July $12^{\mathrm{d}} 15 \cdot 1^{\mathrm{h}}$ and new on July $27^{d} 03 \cdot 9^{\text {h }}$ U.T. The only bright star to be occulted this month is $\lambda$ Piscium, the reappearance of which will be visible from Greenwich on July 18 at $2^{\mathrm{h}} 22 \cdot 4^{\mathrm{m}}$, at position angle $198^{\circ}$ from the north point of the moon's image. Lunar conjunctions with the planets occur as follows: with Jupiter on July $16^{\mathrm{d}} 7^{\mathrm{h}}$; with Saturn on July $20^{\mathrm{d}} 0^{\mathrm{h}}$; with Mercury on July $29^{\mathrm{d}} 5^{\mathrm{h}}$; and with Venus on July $30^{\mathrm{d}} 9^{\mathrm{h}}$. On July 26, Mercury is near Regulus, the minimum apparent separation (geocentric) being $0.9^{\circ}$; and on July $31^{\mathrm{d}} 7^{\mathrm{h}}$ Mercury is in conjunction with Neptune, the separation being $0 \cdot 4^{\circ}$. Venus is a bright evening star, setting about $1^{\mathrm{h}} 40^{\mathrm{m}}$ after the sun in mid-July. Jupiter and Saturn are both visible during the night, Jupiter, a very bright object, southing about $2 \frac{1}{2}^{\mathrm{h}}$ in the middle of the month and Saturn three hours later. The interesting phenomena (eclipses, transits, occultations) of the Jovian four inner satellites may be followed with the help of the table and diagram given on p. 613 of the Nautical Almanac for 1938 or of the table on p. 170 of Whitaker's Almanack. At $22^{\mathrm{h}}$ in mid-July, Vega is nearing the southern meridian and precedes the Milky Way. The bright star Deneb ( $\alpha$ Cygni) on the galactic equator marks the apex of the bifurcation of the Milky Way, one branch passing southwards through Serpens and Scorpio; the other through Aquila, Scutum and Sagittarius. Interesting objects for telescopic examination abound in this region, which is also the habitat of the novæ. The 6th magnitude double-star, 61 Cygni, was the first star to have its distance successfully measured one hundred years ago by Bessel, who made his measures with a heliometer. His results gave the star's distance as 640,000 times that of the earth-sun distance; modern measures give 680,000 times this unit.

\section{Announcements}

The Right Hon. Neville Chamberlain has been elected a fellow of the Royal Society under Statute 12, which provides for the election of persons who "either have rendered conspicuous service in the cause of science, or are such that their election would be of signal benefit to the Society". 